\title{
On some Larval Stages of Fishes.
}

\author{
By
}

J. T. Cunningham, M.A.,

Naturalist to the Association.

With Plates III and IV.

THE six drawings reproduced in Plates III and IV were made at sundry times from stages that I succeeded in obtaining in the years 1889 and 1890. The three stages of the common sole were procured after my quarto book on that fish was completed, and they enable me to supplement the account of the life-history of the species given there.

Fig. 1 represents a larva of Solea vulgaris four days after hatching. The drawing reproduced was made from the living larva on April 26th, 1890 ; the larva was hatched on April 26th from an egg artificially fertilized on April 14th on board a trawler off the north coast of Cornwall. The temperature of the surface water of the sea in which the eggs were fertilized was $9 \cdot 7^{\circ}$ C., of the water in the Laboratory in which the eggs were kept $10 \cdot 8^{\circ} \mathrm{C}$. The variations of temperature in which the eggs were carried while on board the trawling smack were not observed. I can only, therefore, give an approximation to the relation between temperature and the period of development of the egg, namely, that at a mean temperature of about $10.0^{\circ} \mathrm{C}$. the eggs of the sole hatch in eight days.

The condition of the larva of the sole immediately after hatching is described and illustrated in my Treatise on the species. The changes which have occurred in the stage represented in fig. 1 are the following: The yolk, $y k$, is much reduced in bulk, about half the quantity present at hatching having been absorbed. Three groups of oil globules are still visible on the surface of the yolk, the individual globules being larger than in the newly hatched larva, doubtless because some coalescence has occurred. In the newly- 
hatched larva the intestine is straight, and lies in a depression of the dorsal surface of the yolk, while in the present stage the intestine shows the commencement of a convolution above the yolk, and the latter does not project dorsalwards on each side of the gut. The whole of the anterior part of the body is now straightened out, while at the time of hatching it was bent downwards towards the anterior extremity. Accordingly the region of the fore-brain and olfactory organ is now at the anterior extremity of the axis of the body. The position of the olfactory organ is indicated by ol. in the figure, although the organ itself was not distinct enough to be represented in the figure when the drawing was made. The intestine or alimentary tube has now grown forwards beneath the brain to meet the skin beneath the fore-brain and eyes, and the lumen or cavity of the tube, open in the posterior part, is faintly indicated anteriorly by a line; the mouth, however, is not yet open, although the lumen of the gut extends to the exterior at the anus. The heart, $h t$., has the usual structure in larval fish at this stage ; it consists of a tube beneath the gullet having an aperture posteriorly, by which it communicates with the perivitelline sinus. The heart is surrounded by a cavity, which is separated from the perivitelline sinus by a delicate membrane, and which is afterwards extended to form the body-cavity. Pigment has begun to appear in the eye, $i . e$. in the choroid membrane, as separate dots. The mid-brain, $m$. b., projects dorsally. The primordial membranous fin of the larval sole is characterised by its irregularity of outline anteriorly. The edge of this fin forms a projection over the mid-brain, and another behind the head. The pigmentation of the skin consists of black and yellow dendritic ( $i . e$. branched) chromatophores. On the fin these chromatophores form four not very definitely marked spots on the dorsal portion, and one posteriorly on the ventral portion. At later stages these spots become more definite and conspicuous. The total length of the larva represented in fig. 1 was $4.35 \mathrm{~mm}$.

Fig. 2 shows an older larva from the same lot. It was drawn on April 28th, that is, six days after hatching. The mouth is now fully developed, although a remnant of the yolk is still unabsorbed, and the larva has not yet begun to feed. The eye is now completely pigmented, the choroid membrane being black and opaque. The auditory vesicle, in the previous stage a simple spherical capsule with two calcareous nodules inside it, is now much enlarged, and exhibits the commencement of the semicircular canals within it. The olfactory organ, ol., has the form of a spherical capsule just beneath the skin, opening to the exterior by a circular aperture. There is, of course, one of these on each side of the snout; the 
division of each aperture into the two nostrils which exist on each side in the adult takes place later. The convolution of the intestine, although still simple, is much larger and more conspicuous in consequence of the increase of the intestine in length. The heart has the same relations as in the previous stage. The pectoral fin is visible as a somewhat quadrangular membranous fold projecting from the side of the body behind and below the auditory organ. The great bluntness of the anterior edge of the head is very characteristic of the larval sole at this stage. The mid-brain is still very prominent dorsally. The dorsal edge of the primordial fin still presents the two rounded projections described in the previous stage. The pigmentation of the skin is now more developed than before. The length of the larva from which fig. 2 was prepared was $4.2 \mathrm{~mm}$., rather less than that of the specimen represented in fig. 1. Fig. 2 represents the appearance of the larva as seen partly by reflection, partly by transmission of the light; the light was partly excluded from the aperture of the stage of the microscope, so that the specimen was seen against a somewhat dark background, as shown in the figure.

The stage shown in fig. 2 is the oldest which I have examined in larvæ reared in confinement from artificially fertilized ova; all the larvæ I reared last year, died soon after this stage was reached. Fig. 3 shows the appearance during life of an older larva which I obtained in Cawsand Bay, Plymouth Sound, on May 14th, 1890. It was captured in a small trawl made of cheese-cloth and worked on a sandy bottom in three to five fathoms of water. I think there can be no doubt that this larva belonged to Solea vulgaris. I identify it by the distribution of the pigment in the skin, especially the spots on the dorsal and ventral fin, and by the shape of the head. The tissues of the body, though still translucent, were no longer transparent enough at this stage to show the internal organs so clearly as at the stages previously described. The chief features to notice at this stage are as follows. The notochord is bent upwards at its posterior extremity, and the caudal fin-rays are beginning to appear beneath the bent portion. The lateral muscles of the body are defined dorsally and ventrally by a distinct margin, between which and the base of the median fin-membrane is a region in which the interspinous bones, $i s$. $b$., have begun to appear. The liver, $l$., is visible as a large mass towards the anterior margin of the abdominal cavity. Behind the intestine, int., is seen the urinary bladder, $u . b$. The prominence of the mid-brain and the projections of the outline of the longitudinal fin over the head have disappeared, but the fin membrane still extends forwards in front of the eyes. The eye has a blue colour, probably due to iridescence of the 
choroid membrane. The auditory vesicle is very large, and extends dorsalwards far above the level of the eyes. The pigmentation of the skin is characterised by the development of very definite spots along the sides of the dorsal and ventral fin membrane. In the centres of these spots as well as over the sides of the body there are small orange spots in addition to the yellow and black of the earlier stages. Judging from what I have seen in the skin of the adult plaice and sole, I believe that the orange is not a new pigment, but the same pigment as the yellow in a more concentrated form; in fact $I$ have reason to conclude that there are only two pigments in the skin of flat fishes, the black and the yellow, the latter being yellow when spread out, orange or even red when concentrated into a thicker globule. It will be seen on comparison that my fig. 3 differs very greatly from the figure of a larval sole of about the same size, $5 \mathrm{~mm}$., given by Professor McIntosh in Plate III of the seventh Annual Report of the Scottish Fishery Board. We do not know the whole development of the sole with sufficient completeness to justify a definite assertion on the matter, but I cannot help doubting for the present whether Professor McIntosh's figure represents a stage of the larval sole at all.

In my paper published in this Journal March, 1889, I was unable to describe the larva of the mackerel. In the summer of that year I succeeded in hatching some artificially fertilized ova of the species, but could not keep them alive for any length of time. Pressure of other work has prevented me since from devoting much attention to the mackerel, and all I have to add now is a figure of the newly hatched larva, fig. 4. The drawing reproduced in this figure was made on July 2nd, 1889. The egg, from which the larva hatched, was one of a number artificially fertilized for me by mackerel fishermen on board their own boats. The length of the larva was $4.23 \mathrm{~mm}$. In structure the larva does not differ essentially from other species belonging to the Physoclisti, or Teleosteans with closed air-bladders.

As in most other larvæ of that division, the rectum is immediately behind the short oval anterior yolk-sac. The notochord is as usual multicolumnar, composed of several columns of cells. The mouth is not open, and the eye (choroid membrane) is unpigmented. The slender elongated form of the larva is characteristic. But the chief distinguishing feature is the pigment of the skin and its distribution. The pigment consists of chromatophores of two colours, black and green, as in the adult. There is no pigment at all on the primordial median fin membrane. Black chromatophores occur over the sides of the body and head, especially along the edges of the body. The green chromatophores, mingled with black, occur only 
in five spots in the neighbourhood of the yolk-sac. The largest of these is not in the skin, but on the surface of the yolk-mass over the oil-globule, which is situated at the posterior end of the yolk. Another is at the base of the rudiment of the pectoral fin, pe. $f$. Another is just behind the eye, and two others are at the anterior end of the yolk-sac.

The larva represented in fig. 5, Plate IV, is that of Cottus bubalis, a species extremely common on the shore at Plymouth. The eggs of this species are adhesive and are deposited in small rounded clumps of about one and a half to two inches in diameter attached to stones or rocks on the shore. There are usually numbers of the fish in our tanks, where they regularly deposit their eggs. The deposition of the eggs takes place in January, February and March. The single egg is $1.7 \mathrm{~mm}$. in diameter, and is characterised by the presence of rounded protuberances all over the external surface of the envelope. The yolk when the egg is first laid has usually several rather large oil-globules, but during development these coalesce into a single globule. Fig. 5 shows the appearance and structure of the living larva immediately after hatching. The larva is in a much more advanced condition than those of species hatched from pelagic eggs. Its length is $5.7 \mathrm{~mm}$. The mouth is open and the cartilaginous branchial arches are already formed. The choroid of the eye is fully pigmented, and has a deep blue colour by reflection. Some of the yolk still remains and the oil-globule is situated at its anterior surface. The condition of the heart is quite different from that seen in newly hatched pelagic larvæ; instead of a continuous perivitelline blood sinus, there are numerous definite vitelline vessels, $v . v$, and in these, circulates fully developed red blood, containing numerous red corpuscles. These vitelline vessels lead to the posterior end of the heart, and in the opposite direction are seen to be continuous with the vessels of the liver $l$. On the dorsal side of the liver, in the figure, is seen the gall-bladder, conspicuous from the green colour of its contents. Above the liver is seen the enlargement of the intestinal tube forming the stomach, but the tube is without convolutions. The notochord is multicolumnar, and below it are seen the caudal artery and vein, c. v., in which the blood is seen in the living larva coursing in opposite directions. The pectoral fin, pe. $f$., is large and membranous, with a semicircular outline. The auditory vesicle with its two calcareous nodules, and developing semicircular canals, is a conspicuous structure behind the eye. The distribution of pigment in the larva is peculiar. Black pigment only is present, yellow not being developed till a later stage. Pigment is altogether absent from the caudal region; the black chromatophores are almost en- 
tirely confined to the dorsal region of the peritoneum, where they are closely aggregated in a saddle-shaped area over the region of the stomach and rectum. There are also a few chromatophores in the skin behind the base of the pectoral fin. Professors McIntosh and Prince* give a figure of a later stage identified by them as belonging to Cottus scorpius; the latter species is abundant on the Scottish coast, but I have not yet met with it at Plymouth. Their figure shows little detail, and they do not note the fact that the characteristic saddle of black pigment is situated in the peritoneum and not in the skin. In the larva figured by them yellow pigment is present on the head and abdominal region.

Fig. 6, Plate IV, represents an advanced larval stage identified as belonging to the grey mullet Mugil chelo. The little fish was taken in Mevagissey Harbour and sent to our Laboratory alive by Mr. Matthias Dunn, on May 10th, 1890. I have identified it by the shape of its head and snout, and by comparison with more advanced young of the same species which occur abundantly near Plymouth in summer. It was $10.5 \mathrm{~mm}$. in length. The yolk is entirely absorbed, and the body opaque and pigmented. But the fins still retain their larval membranous character, the formation of the fin-rays having only commenced in the caudal region beneath the upturned extremity of the notochord. The air-bladder, $a . b$. , is conspicuous; the pectoral fins are large. The pigmentation of the skin is a general yellow ground with numerous black chromatophores scattered over it ; the yellow colour would, of course, also be resolved into chromatophores under a higher magnifying power.

Raffaele in his paper in the Mittheilungen of the Zoological Station at Naples, vol. viii, gives figures of the ovum, and the newlyhatched larva of a species of Mugil or mullet. The ovum is pelagic and small, it has a single large oil-globule. There is little that is characteristic in the figure of the newly-hatched larva, except that the yolk is ellipsoidal instead of spherical, and the pigment is yellow and black as in the stage I have above described.

* Development of Teleostean Fishes, Trans. Roy. Soc., Edinb., vol. xxxv, pt. iii, 1890. 


\section{DESCRIPTION OF PLATES III AND IV,}

Illustrating Mr. Cunningham's paper "On Some Larval Stages of Fishes."

Reference Letters.

a. b. Air bladder. au. Auditory organ. c. v. Caudal blood-vessels. ht. Heart. int. Intestine. is. $b$. Interspinous bones. $l$. Liver. m. b. Mid-brain. pe.f. Pectoral fin. $u$. $b$. Urinary bladder. $v . v$. Vitelline blood-vessels. $y k$. Yolk.

\section{PLATE III.}

FIG. 1.-Larva of Solea vulgaris, from egg artificially fertilized. Hatched April 22nd, drawn April 26th, 1890. Zeiss, $a_{3}$, oc. 3, camera.

FIG. 2.-Larva of Solea vulgaris, hatched same date, drawn April 28th. Zeiss, $\mathrm{a}_{3}$, oc. 3 , camera.

FIG. 3.-Larva of Solea vulgaris, caught in Cawsand Bay, May 14th, 1890.

\section{PLATE IV.}

Fig. 4.-Larva of Scomber scomber (mackerel), newly hatched. Zeiss, $a_{3}$, oc. 3, camera.

Frg. 5.-Cottus bubalis, newly hatched. Zeiss, $\mathrm{a}_{3}$, oc. 3 , camera.

FIG. 6. Larva of Mugil chelo (grey mullet). Zeiss, $\mathrm{a}_{3}$, oc. 2, camera. 


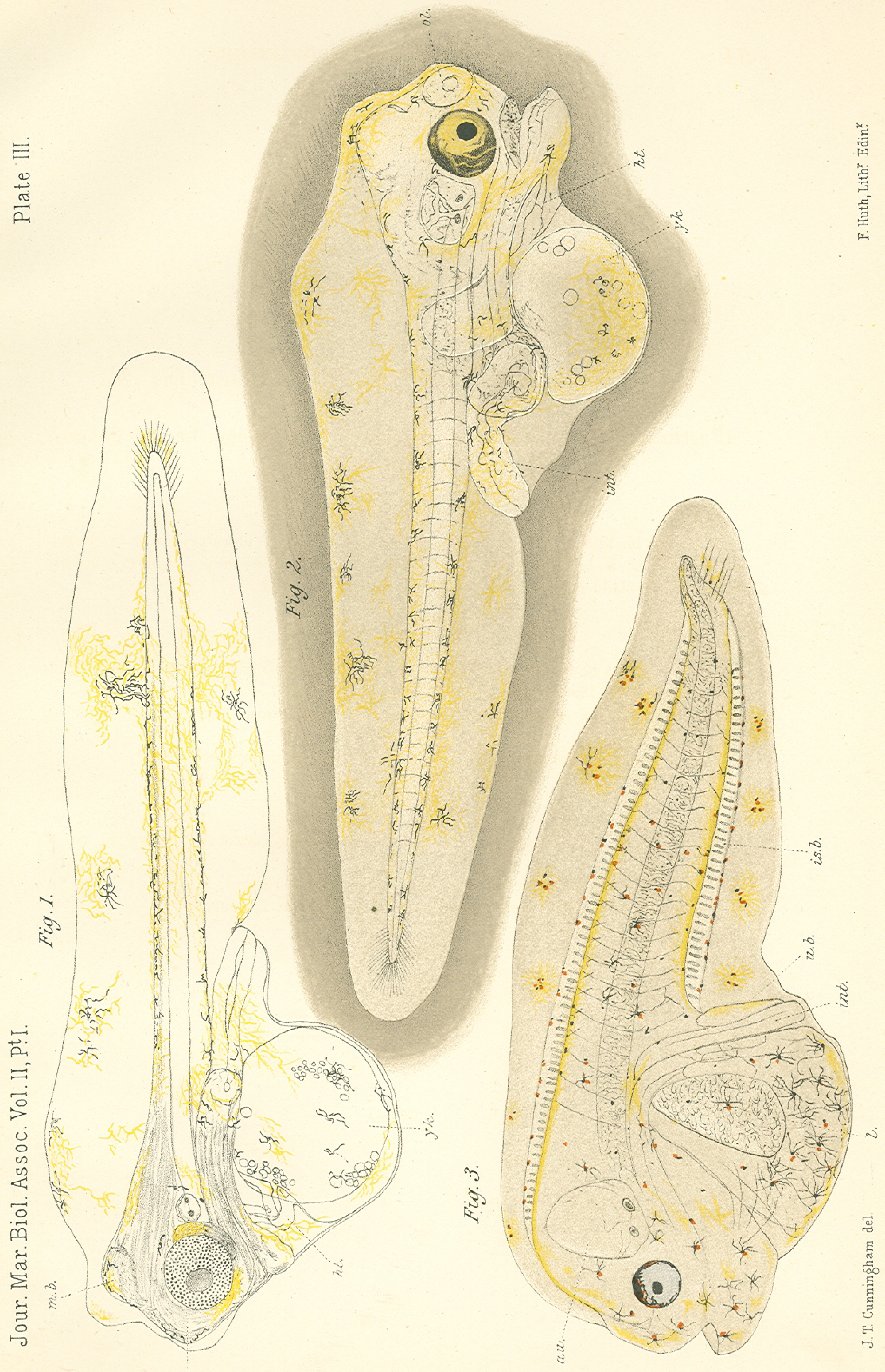


0
0
0
0
0

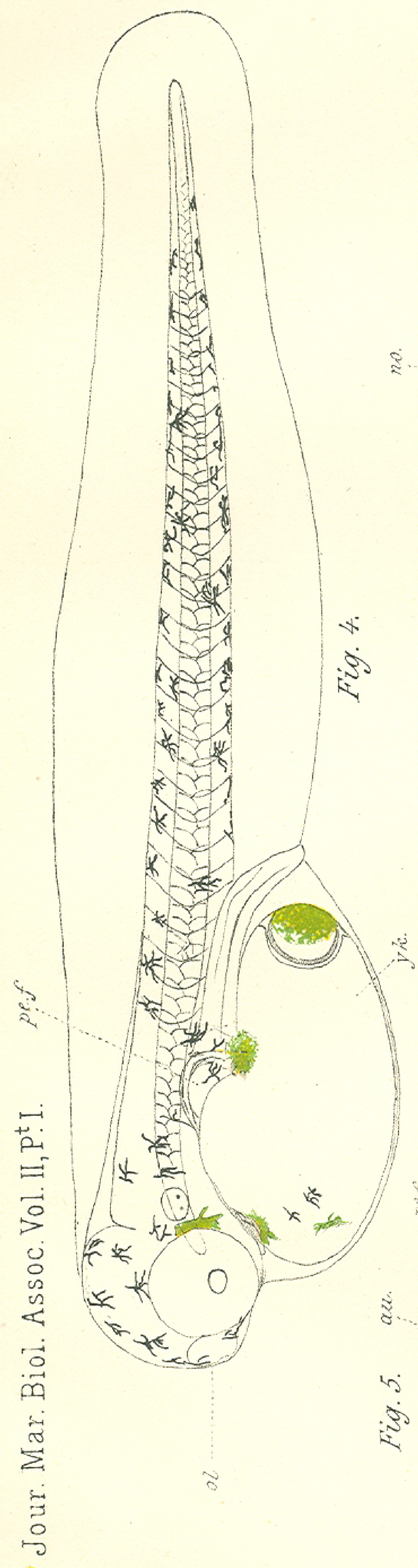

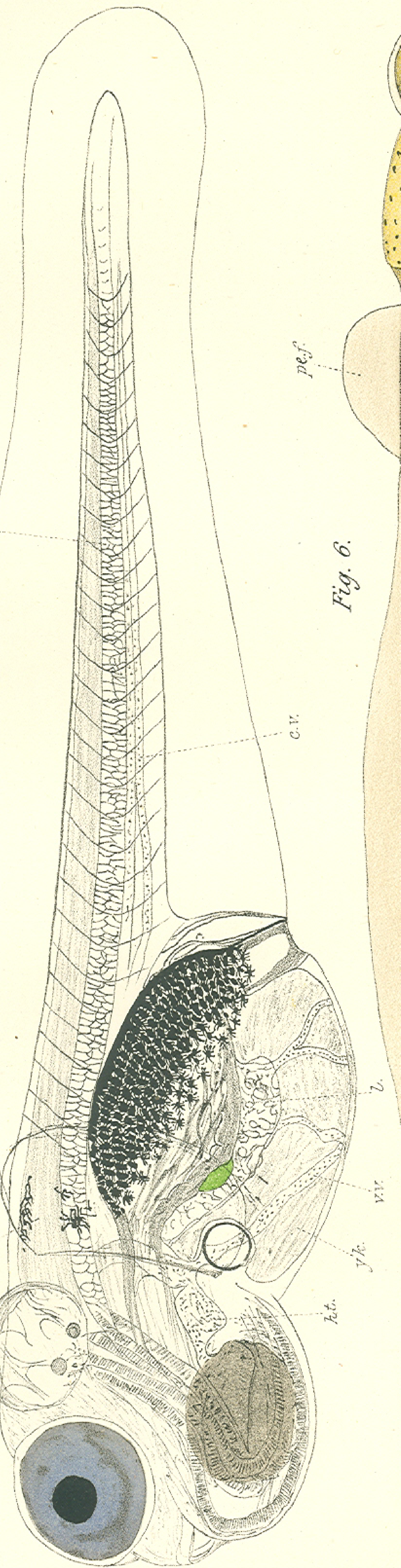

焉

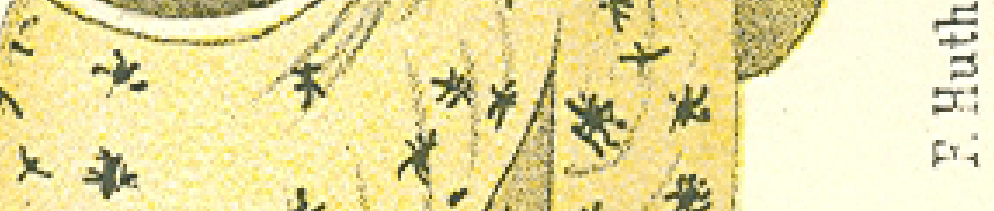

.

$\therefore \%$ * *

$4 x^{2}+x^{-k}$

$* x+2$

* $=x^{2} x$

$\because x_{*}^{*}+x+4 ;$

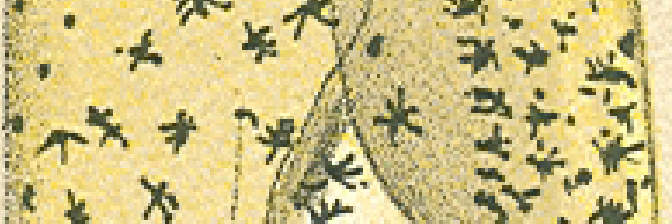

$+x$ t

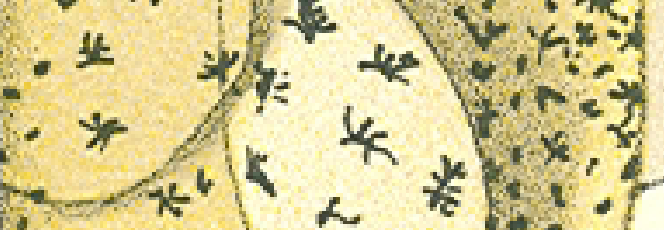

$\therefore: x^{*} x^{2}+x^{*}$

$\because k * * k^{k} k^{k} \ldots$

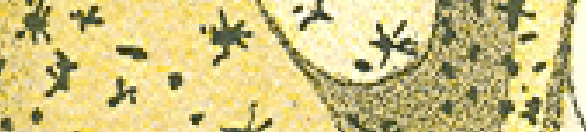

$\therefore \forall . * *+\gamma$

.

$x x^{2}=x$

$\therefore x^{*} * x^{2}$

$\because x^{x} x^{4} \cdot x^{4}$

$\therefore x+x=x$

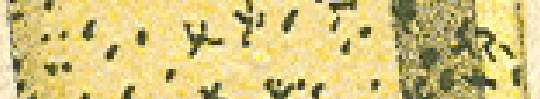

$\because \therefore x+x=2$

$\because \because \div x+2=$

$\because \therefore ?-$

$\because \because \because \because \because \therefore$

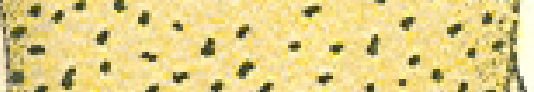

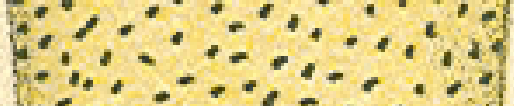

$\because$
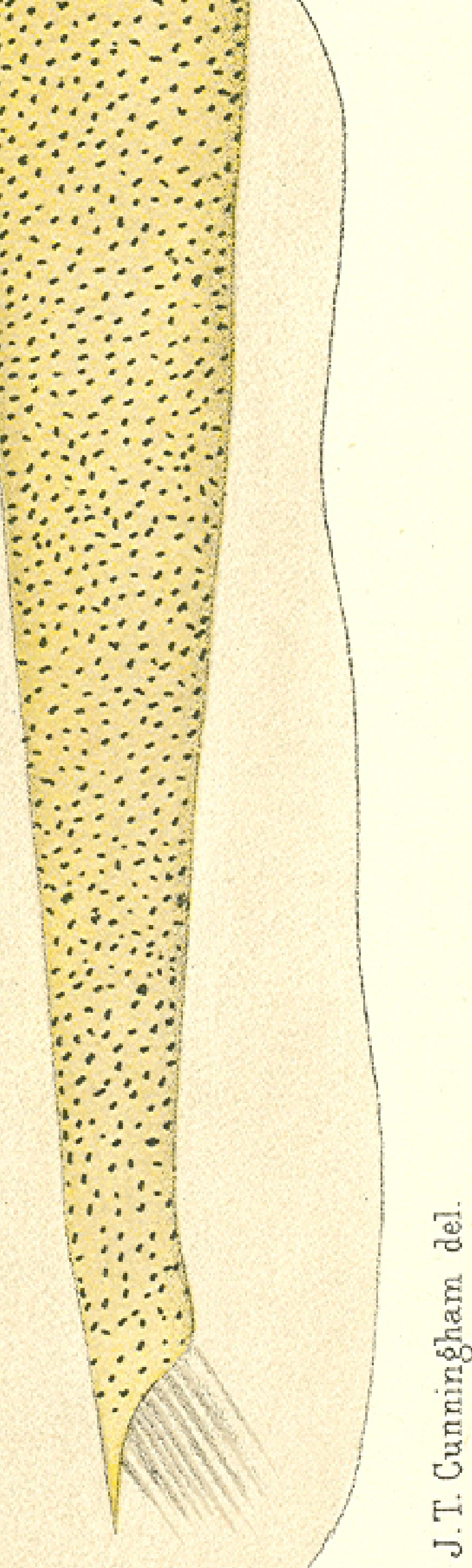